\title{
Natural History of Radiologic Incisional Hernia Following Robotic Nephrectomy
}

\author{
Alireza Ghoreifi, MD, ${ }^{1}$ Gilbert Whang, MD, ${ }^{2}$ Khoa Tran, MD, ${ }^{2}$ Tapas Tejura, MD, ${ }^{2}$ Benjamin Liu, BS, \\ Jie Cai, MS, ${ }^{1}$ Xiaomeng Lei, MS, ${ }^{2}$ Steven Cen, PhD, ${ }^{2}$ Mohammad Aslzare, MD, ${ }^{3}$ Madeleine Burg, MD, \\ Mihir Desai, MD, ${ }^{1}$ Monish Aron, MD, Inderbir Gill, MD, ${ }^{1}$ Vinay Duddalwar, MD, ${ }^{2}$ and Hooman Djaladat, MD, MS ${ }^{1}$
}

\begin{abstract}
Objective: To evaluate the incidence and natural history of radiologic incisional hernia (IH) in patients who underwent robotic partial or radical nephrectomy.

Materials and Methods: We retrospectively reviewed the records of patients who underwent robotic partial or radical nephrectomy for kidney tumor in our institution between January 2011 and April 2017. All pre- and postoperative imagings were re-reviewed for detection of IH per Tonouchi classification. Patients who developed hernia were followed up and classified into stable or progressive group. Clinical findings and radiologic features of these patients are reported.

Results: A total of 247 patients (169 partial and 78 radical nephrectomies) were included in the study. The incidence of radiologic IH was $27.53 \%$, graded as early-onset $(35.3 \%)$, late-onset $(51.5 \%)$, and bowel/fat containing (13.2\%). Median time to radiologic IH was 1.7 years. During the follow-up of 68 patients who developed hernia, $33(48.5 \%)$ had progressive and 8 (11.7\%) developed clinical hernia. Median time to progression was 1.5 years. On multivariable analysis, adjuvant therapy was an independent predictor for radiologic hernia development (HR 3.23). Pathologic $T$ stage $\geq 2$ and history of open abdominal surgery were also significantly associated with hernia progression (HR 3.93 and 3.47, respectively).

Conclusions: Radiologic IH after robotic partial or radical nephrectomy is common. Progression rate is as high as $50 \%$ with median time to progression of 1.5 years. Adjuvant therapy is an independent predictor for $\mathrm{IH}$ development, whereas higher stage and history of open abdominal surgery are associated with IH progression.
\end{abstract}

Keywords: incisional hernia, robotic surgical procedures, nephrectomy

\section{Introduction}

$\mathbf{M}$ INIMALLY INVASIVE UROLOGIC surgery has gained widespread acceptance in recent years because of improved postoperative recovery and cosmetics compared with open approaches. ${ }^{1}$ Increased utilization of these minimally invasive approaches has led to the emergence of new types of complications, including incisional hernia (IH). IH may be occult or symptomatic; presenting with pain, bulge, bowel incarceration, strangulation, and increased morbidity and mortality rates. ${ }^{2,3}$ Since 1968 that Fear reported the first case of IH in a cohort of gynecologic laparoscopic patients, ${ }^{4}$ several reports regarding incidence, risk factors, and treatment of IH have been published. Nevertheless, few publications are available in urologic literature that is mainly based on small sample-sized and poorly defined follow-up studies. ${ }^{5}$
Furthermore, there is little available data on the natural history of radiologic IH even in nonurologic studies. The aim of this study is to evaluate the incidence, characteristics, and natural history of radiologic $\mathrm{IH}$ in patients who underwent robotic partial or radical nephrectomy for kidney tumor.

\section{Material and Methods}

\section{Patients and variables}

Using our institutional review board-approved renal mass database, we retrospectively reviewed all patients who underwent robot-assisted partial or radical nephrectomy for renal cancer between January 2011 and April 2017. During this time frame, a total number of 575 robotic partial/radical nephrectomy was performed in our institution. Patients without available 6-month preoperative high-quality abdominopelvic

\footnotetext{
${ }^{1}$ Institute of Urology, University of Southern California, Los Angeles, California, USA.

${ }^{2}$ Department of Radiology, University of Southern California, Los Angeles, California, USA.

${ }^{3}$ Department of Urology, Mashhad University of Medical Sciences, Mashhad, Iran.
} 
CT scan, history of abdominal surgery with mesh repair, open abdominal operation within 1-year after surgery, or without available postoperative images/lost to follow-up were excluded. Clinical features, including age, gender, Charlson Comorbidity Index (CCI), American Society of Anesthesiologists (ASA) score, body mass index (BMI), smoking, underlying chronic obstructive pulmonary disease or asthma, and history of previous abdominal surgery (open, laparoscopic, and robotic) were captured. Operative and treatment details, including side and type of surgery (partial/radical nephrectomy), surgical approach (retro/transperitoneal), operative time, estimated blood loss, ischemia time (for partial cases), pathologic type/stage, and adjuvant therapy for cancer (chemo, immuno, and/or radiotherapy) were also recorded. Clinical IH was defined as bulging or protrusion of the peritoneum, omentum, or intestine through the trocar site or extraction site, which was confirmed in the physical examination.

\section{Surgical procedure}

The nephrectomies were done using Da Vinci Si or Xi surgical system. Five to seven trocars were generally used for each procedure, including three/four $8-\mathrm{mm}$ robotic trocars and one to three 5-12-mm assistant trocars. The midline and lateral ports were established using longitudinal and horizontal incisions, respectively. All but eight of the specimens were extracted from the extended port sites. The fascia was routinely closed on $12 \mathrm{~mm}$ ports using absorbable sutures with or without the Carter-Thomason device. The skin was closed on all ports with 4-0 absorbable suture in a subcuticular manner.

\section{Radiology review}

Three independent experienced radiologists reviewed all pre- and postoperative as well as follow-up imagings for
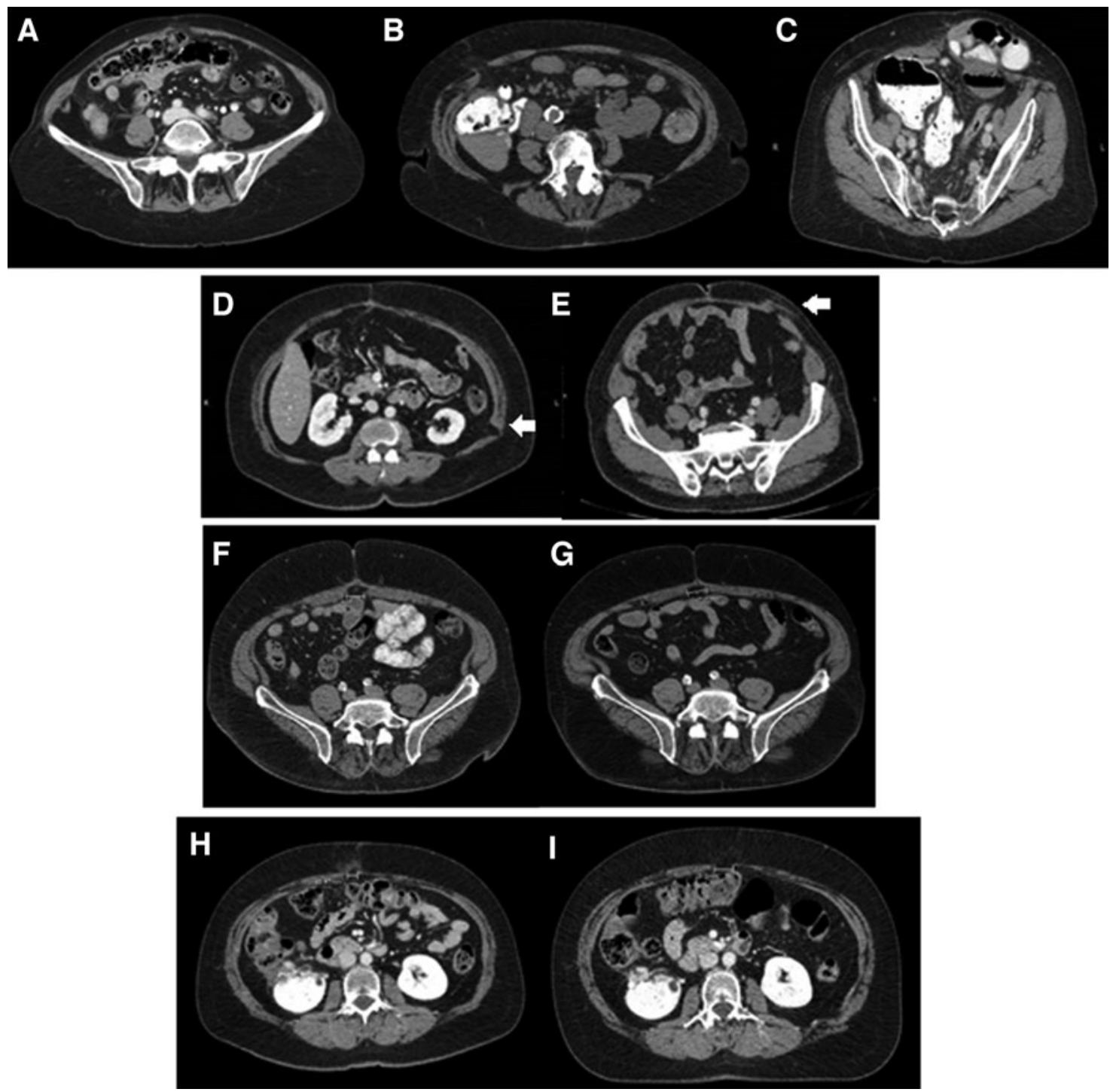

FIG. 1. (A-C) Different types of radiologic IH based on Tonouchi classification: (A) early-onset, (B) late onset, and (C) bowel/fat containing. (D, E) Different types of muscle defects without hernia: (D) partial muscle and (E) full muscle. (F-I) Different types of radiologic IH based on the natural history: (F, G) stable IH during 3 years, (H, I) progressive IH, size change from 10.4 (H) to $18.2 \mathrm{~mm}$ (I) in 2 years. $\mathrm{IH}=$ incisional hernia. 
evaluation of IH. Radiologic IH features, including size, location, and type, were recorded. A high reliability (intra class correlation $[\mathrm{ICC}]=0.94,95 \%$ CI $0.86-0.97$ ) of size measurement, between three radiologists who independently measured the hernia defects on 55 scans (11 patients), was demonstrated by ICC two-way-mixed with absolute agreement. Type of IH was classified based on Tonouchi classification as early-onset, late-onset, and bowel/fat containing type (Fig. 1A-C). ${ }^{2}$ Early-onset was defined as dehiscence of the anterior and posterior fascial plane and peritoneum, lateonset as dehiscence of anterior and posterior fascial plane while peritoneum constitutes hernia sac, and bowel/fat containing type as dehiscence of whole abdominal wall and protrusion of intestine and/or omentum. Muscular defects without hernia were also recorded and classified as partial and full muscle thickness defects (Fig. 1D, E). Patients who developed IH were also followed closely and classified into stable or progressive, based on their subsequent changes. Stable IH was defined as size change $<10 \%$ in follow-ups, whereas progressive $\mathrm{IH}$ as either size change $>10 \%$, upgrading per Tonouchi classification, or becoming symptomatic (Fig. 1F-I).

\section{Results}

\section{Clinical and surgical characteristics}

A total of 247 patients included in this study (Table 1). Mean age of patients was $61.5 \pm 11.8$ (23-95) years, and $71.3 \%$ were men. Mean BMI was $29.9 \mathrm{~kg} / \mathrm{m}^{2}$ (12.4-95.8). One hundred twenty-one (49\%) patients had prior abdominal
FIG. 2. Kaplan-Meier curve estimation of IH progression stratified by history of open abdominal surgery (A) and pT stage (B).

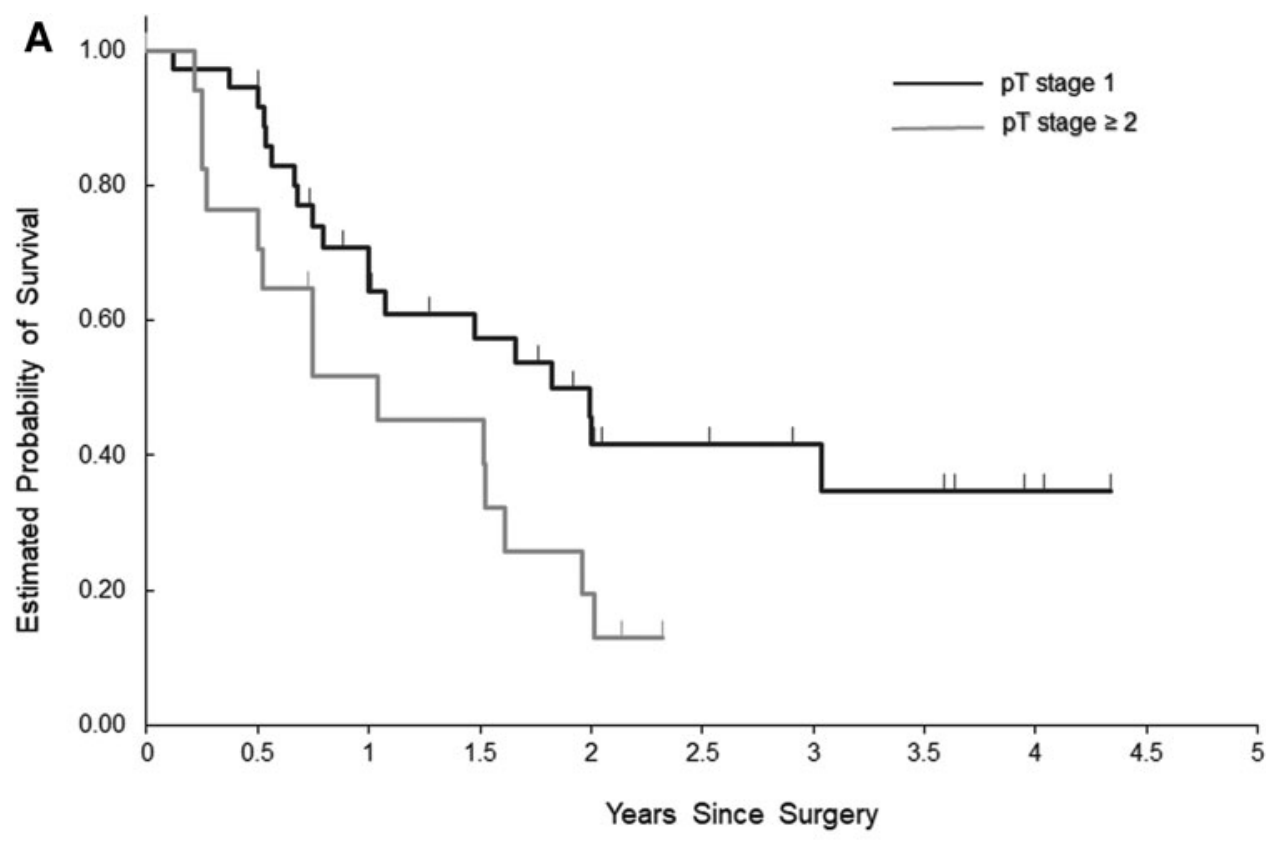

B
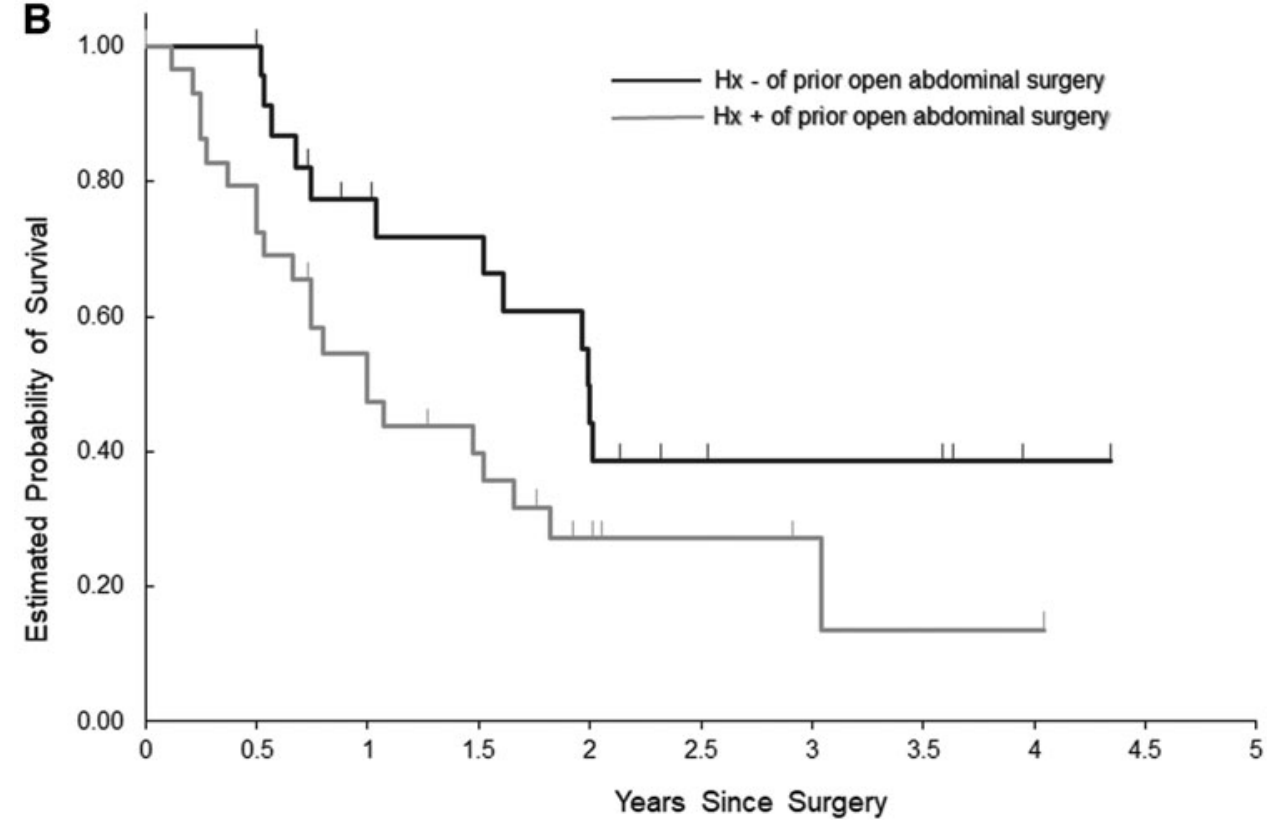
Table 1. Baseline Characteristics and Clinical Features of the Patients

\begin{tabular}{|c|c|}
\hline Variable & Value \\
\hline $\begin{array}{l}\text { Age (years) } \\
\text { Mean } \pm \text { SD (range) }\end{array}$ & $61.5 \pm 11.8(23-95)$ \\
\hline $\begin{array}{l}\text { Gender, } n(\%) \\
\text { Male } \\
\text { Female }\end{array}$ & $\begin{array}{r}176(71.3) \\
71(28.7)\end{array}$ \\
\hline $\begin{array}{l}\text { BMI }\left(\mathrm{kg} / \mathrm{m}^{2}\right) \\
\quad \text { Mean } \pm \text { SD (range) }\end{array}$ & $29.9(12.4-95.8)$ \\
\hline $\begin{array}{l}\mathrm{CCI}, n(\%) \\
\quad 0 \\
\geq 1\end{array}$ & $\begin{array}{l}129(52.2) \\
118(47.8)\end{array}$ \\
\hline $\begin{array}{l}\text { ASA, } n(\%) \\
1-2 \\
\geq 3 \\
\text { Underlying respiratory } \\
\quad \text { disease, } n(\%)\end{array}$ & $\begin{array}{r}102(41.3) \\
145(58.7) \\
26(10.5)\end{array}$ \\
\hline $\begin{array}{l}\text { Smoking, } n(\%) \\
\text { Prior abdominal } \\
\quad \text { surgery, } n(\%)^{\mathrm{a}}\end{array}$ & $\begin{array}{r}84(34) \\
121(49)\end{array}$ \\
\hline $\begin{array}{l}\text { Open } \\
\text { Lap } \\
\text { Robotic }\end{array}$ & $\begin{array}{l}101(41) \\
30(12.1) \\
10(4)\end{array}$ \\
\hline $\begin{array}{l}\text { Type of procedure, } n(\%) \\
\text { Partial nephrectomy } \\
\text { Radical nephrectomy }\end{array}$ & $\begin{array}{r}169(68.4) \\
78(31.6)\end{array}$ \\
\hline $\begin{array}{l}\text { Approach, } n(\%) \\
\text { Transperitoneal } \\
\text { Retroperitoneal }\end{array}$ & $\begin{aligned} 231 & (93.5) \\
16 & (6.5)\end{aligned}$ \\
\hline $\begin{array}{l}\text { Side, } n(\%) \\
\text { Right } \\
\text { Left } \\
\text { Bilateral }\end{array}$ & $\begin{aligned} 131 & (53) \\
115 & (46.6) \\
1 & (0.4)\end{aligned}$ \\
\hline $\begin{array}{l}\text { Operative time (minutes) } \\
\text { Mean } \pm S D \text { (range) }\end{array}$ & $260.7 \pm 80.1(28-580)$ \\
\hline $\begin{array}{l}\text { Estimated blood loss (cc) } \\
\quad \text { Mean } \pm \text { SD (range) }\end{array}$ & $222.9 \pm 265.9(0-2500)$ \\
\hline $\begin{array}{l}\text { Pathologic stage, } n(\%) \\
\text { T1 } \\
\text { T2 } \\
\text { T3 } \\
\text { T4 }\end{array}$ & $\begin{aligned} 184 & (75.5) \\
14 & (5.7) \\
48 & (19.4) \\
1 & (0.4)\end{aligned}$ \\
\hline $\begin{array}{l}\text { Histologic subtypes, } n(\%) \\
\text { Clear cell } \\
\text { Papillary } \\
\text { Chromophobe } \\
\text { Other } \\
\text { Adjuvant therapy, } n(\%)\end{array}$ & $\begin{aligned} & 200(81) \\
& 22(8.9) \\
& 14(5.7) \\
& 11(4.4) \\
& 12(4.9)\end{aligned}$ \\
\hline
\end{tabular}

a 20 patients had $>1$ type of previous surgery.

ASA = American Society of Anesthesiologists; BMI = body mass index; $\mathrm{CCI}=$ Charlson Comorbidity Index.

surgery. Robotic partial and radical nephrectomies were done in 169 and 78 patients, respectively. Transperitoneal approach was done in $231(93.5 \%)$ and retroperitoneal in 16 (6.5\%). Mean operation time was $260.7 \pm 80.1$ (28-580) minutes. In partial nephrectomy cases, mean ischemia time was $16.3 \pm 11.9(0-47)$ minutes. Pathologic stage was T1 (74.5\%), T2 (5.7\%), T3 (19.4\%), and T4 (0.4\%). Twelve $(4.86 \%)$ patients received adjuvant therapy.

\section{Radiologic features}

In a median follow-up of 2.6 (range 1-6.7) years, radiologic $\mathrm{IH}$ was seen in $68(27.5 \%)$ patients. This incidence was not different between partial and radical nephrectomy cases (26.6\% and $29.5 \%, p=0.43$ ). Furthermore, Cox regression modeling indicated that there was no significant difference between intraperitoneal and retroperitoneal approaches in terms of risk of hernia development $(\mathrm{HR}=1.67, p=0.43)$. $\mathrm{IH}$ was graded as early-onset $(35.3 \%)$, late-onset (51.5\%), and bowel/fat containing type (13.2\%). Mean IH size was $13.8 \pm 15.4(1.2-78.2)$ millimeters. The locations were midline $(58.8 \%)$, anterolateral $(36.8 \%)$, and posterior $(4.4 \%)$. None of the eight patients with midline/Pfannenstiel extraction sites developed IH. Median time to radiologic IH was 1.7 years (IQR 0.84-2.52). On multivariable Cox regression analysis, adjuvant therapy was an independent predictor for radiologic IH development (HR 3.23, 95\% CI 1.44-7.27 and $p=0.004$ ). The incidence of partial and full muscle defects was $14.6 \%$ and $6.5 \%$, respectively. Among these patients only one developed radiologic hernia.

During the follow-up of 68 patients who developed IH, 33 $(48.5 \%)$ had progressive IH. Median time to progression was 1.5 years. Pathologic $\mathrm{T}$ stage $\geq 2$ and history of open abdominal surgery were significantly associated with IH progression (HR 3.93, 95\% CI 1.74-8.89, $p=0.001$ and HR 3.47, 95\% CI $1.53-7.93, p=0.003$, respectively) (Fig. 2). Among 34 patients who had previous open abdominal surgeries, $13(38.2 \%)$ had a history of umbilical and/or inguinal hernia repair.

\section{Clinical IH}

Overall incidence of clinical IH in our cohort was 3.2\%. Characteristics of the eight patients with clinical IH are shown in Table 2. All of these patients had a history of prior abdominal surgery of which $75 \%$ were open. The median BMI was $34.4 \mathrm{~kg} / \mathrm{m}^{2}$. All of the surgeries were done as transperitoneal approach. Among eight clinical IH, seven (87.5\%) were bowel/ fat containing. Median clinical IH size was $47.5 \mathrm{~mm}$. Median time from surgery to clinical IH development was 2.5 years.

\section{Discussion}

The data on the development and natural history of radiologic IH after minimally invasive urologic procedures are sparse. We reported the incidence and outcome of radiologic $\mathrm{IH}$ in a homogenous cohort of patients who underwent robotic nephrectomy. Our results indicate that radiologic IH after robotic partial or radical nephrectomy is common, although only small number of patients will become symptomatic clinically.

Radiologic IH can be objectively documented based on imaging data. We found radiologic $\mathrm{IH}$ in $27.5 \%$ of our patients, which is higher compared with the few available data. Christie et al. reported the incidence of radiologic port-site hernia in $6.7 \%$ of 104 patients who underwent robotic urologic oncologic surgeries. ${ }^{6}$ Higher incidence has been shown in nonurologic studies especially in bariatric surgeries. A recent systematic review and meta-analysis of bariatric surgeries reported an incidence of $24.5 \%$ in studies where the hernia was the primary outcome. ${ }^{7}$ Widmar et al. also reported radiologic $\mathrm{IH}$ in $17.4 \%$ and $22.2 \%$ of the patients after robotic and laparoscopic right hemicolectomy, respectively. ${ }^{8}$ The high incidence of radiologic IH in our study was caused by the longer time of follow-up, which included more post-op 


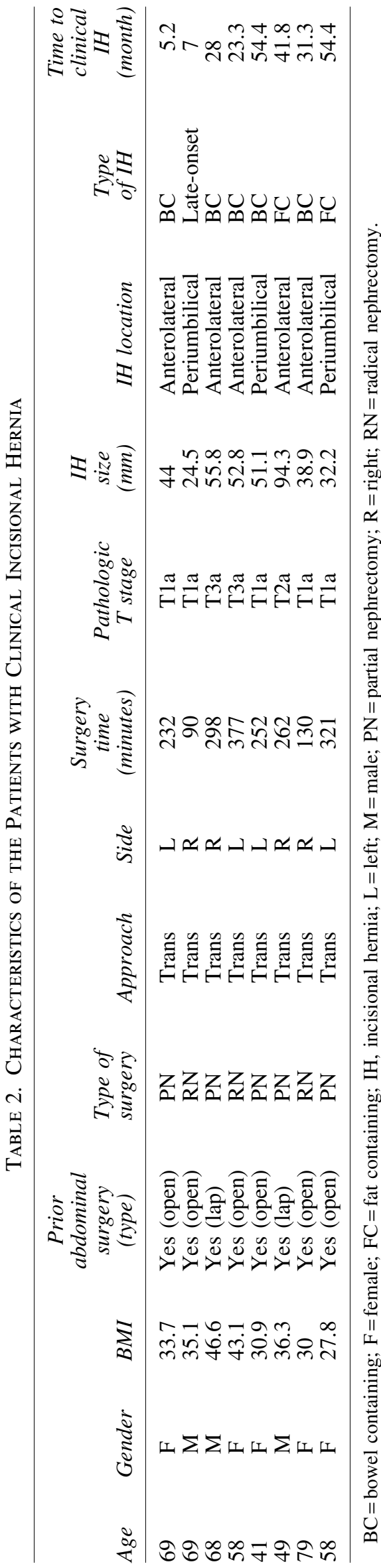

CT scans. Furthermore, we re-reviewed all the CT images and recorded even the subcentimeter small hernias that were missed in the initial readings. It should be noted that the incidence of IH in our study is limited to the current cohort of robotic nephrectomy for renal cancers and may not necessarily represent the total incidence of IH after minimally invasive urologic surgeries.

IH can develop from a few days to several months after surgery. ${ }^{9-11}$ Tonouchi et al. classified IH of the trocar site for the first time, which was mainly based on the radiologic features but also associated with chronological changes. Based on their report, early-onset hernia develops in the early stages after surgery, whereas the late-onset type is seen almost always several months after surgery. ${ }^{2}$ It has been shown that half of the $\mathrm{IH}$ occurs during the first postoperative month. ${ }^{5}$ Similar to the previous studies we found radiologic $\mathrm{IH}$ in a wide range of time ( 9 days to 6.7 years). However, the median time to radiologic $\mathrm{IH}$ was 1.7 years and the late-onset IH was the most prevalent type. These results necessitate a thorough physical examination in each follow-up visit, even long time after minimally invasive surgery.

Different surgical-related predisposing factors might play a role in the development of IH after minimally invasive surgeries, which include entry techniques (cutting vs blunt trocars), size and location of the trocars, closure of the fascia, and extended operative time. ${ }^{5,12}$ Most of the previous studies that mainly addressed clinical trocar-site $\mathrm{IH}$ reported that the hernias are more prevalent at the trocar sites of $\geq 10 \mathrm{~mm}$ diameter. Furthermore, it seems that using cutting trocars and failure to close or inadequate closure of the fascial defect increases the risk of herniation. ${ }^{5,13} \mathrm{In}$ our series, blunt trocars were used in all patients and all trocar sites $\geq 10 \mathrm{~mm}$ were closed with absorbable sutures. Our study showed that the incidence of radiologic IH was higher in midline. Several authors have showed similar results. ${ }^{14}$ In addition to the anatomical features (i.e., less muscular support in the midline abdominal wall), the use of lager trocar size (12 $\mathrm{mm}$ assistant ports) and the preference of surgeons to extend the midline ports for extraction of specimen are the important factors that may contribute in the higher incidence of $\mathrm{IH}$ in this area. The surgical approach (transperitoneal $v s$ retroperitoneal) has also been studied as a risk factor for $\mathrm{IH}$ development. A systematic review of patients who had laparoscopic radical nephrectomy showed no difference between these two approaches in terms of postoperative wound complications, including $\mathrm{IH}^{15} \mathrm{We}$ found similar results in our study.

There are also different patient-related variables that have been proposed, yet not confirmed as the predisposing factors for $\mathrm{IH}$. These variables include female gender, age $>60$, obesity, diabetes and other comorbidities, smoking and preexisting fascial defect. ${ }^{5,12,16}$ We reviewed all these variables in our study and adjuvant therapy for kidney cancer was the only significant risk factor for radiologic IH development (HR 3.2). Some previous reports showed similar relationship between IH and adjuvant chemotherapy for cancer. ${ }^{17}$ Targeted therapies, including tyrosine kinase inhibitors, which are used in kidney cancer, mainly target rapidly dividing tumor cells. However, other high turnover cells, including macrophages and fibroblasts involved in wound healing, are also being affected,${ }^{18}$ which may associate with fascial defect and predispose the patient to develop $\mathrm{IH}$.

There are few data on the natural history of the radiologic $\mathrm{IH}$ in the literature. Our study showed that almost half of these occult hernias will progress during 1.5 years; yet only $11.7 \%$ 
will become symptomatic (i.e., need repair). The same result is reported by Rebibo et al., which reported 5 symptomatic hernias out of 43 radiologic trocar-site $\mathrm{IH}$ (incidence 11.6\%) after laparoscopic sleeve gastrectomy. No significant risk factor for development or progression of $\mathrm{IH}$ has been found in this study. ${ }^{19}$ Our data showed that pathologic T stage $\geq 2$ (HR 3.93) and history of open abdominal surgery (HR 3.47) were significantly associated with IH progression. It is worth mentioning that $38 \%$ of these previous open abdominal surgeries included umbilical and/or inguinal hernia repair. In a series of laparoscopic cholecystectomy, it has been shown that trocar-site IH is more prevalent in patients with preexisting umbilical hernia. ${ }^{20}$ However, Mayol et al. could not find previous abdominal surgery as a risk factor for IH after laparoscopic surgery. ${ }^{21}$

In our study, $3.2 \%$ of patients developed symptomatic $\mathrm{IH}$ that required surgery. Our results are in the same line as previous studies that mainly included nonurologic surgeries and reported the incidence of $0 \%$ to $5.2 \% .^{5,22}$ There are few studies in urology literature reporting clinical IH. Carlsson et al. using the Surveillance, Epidemiology, and End Results (SEER)Medicare data set reported the frequency of IH repair of 5.3\% after minimally invasive radical prostatectomy in a median follow-up of 3.1 years. ${ }^{23}$ Chiong et al. also reported a total of 7 trocar-site IH out of 1055 consecutive patients who underwent laparoscopic urologic oncology surgery (incidence $0.66 \%$ ). ${ }^{9}$ Nevertheless, there is possibility that the true incidence of clinical IH is under-reported; this may be because of retrospective nature of these studies that are mainly based on risk of IH repair rather than detailed history and physical examination.

Our study is not devoid of limitations. An important one is its retrospective nature that may underestimate the incidence of clinical hernia. Furthermore, we could not meticulously separate different trocar site (i.e., 5, 8, 10, and $12 \mathrm{~mm}$ ) than extraction site hernia if no separate incision was made. However, our study is strong as it included a large number of homogenous patients who underwent standardized surgery by highly skilled minimally invasive urologists in an academic center. Furthermore, long-term follow-up of radiologic features was done by an expert radiology team.

\section{Conclusions}

Radiologic IH is not uncommon after robotic nephrectomy occurring in $27.5 \%$ of cases. In a median follow-up of 1.5 years, progression rate is as high as $50 \%$, although overall $3.2 \%$ become symptomatic. We found adjuvant cancer therapy as an independent predictor for IH development, whereas higher stage and history of open abdominal surgery were associated with IH progression.

\section{Author Disclosure Statement}

No competing financial interests exist.

\section{Funding Information}

No funding was received for this article.

\section{References}

1. Skolarus TA, Zhang Y, Hollenbeck BK. Robotic surgery in urologic oncology: Gathering the evidence. Expert Rev Pharmacoecon Outcomes Res 2010;10:421-432.
2. Tonouchi H, Ohmori Y, Kobayashi M, et al. Trocar site hernia. Arch Surg 2004;139:1248-1256.

3. Duron JJ, Hay JM, Msika S, et al. Prevalence and mechanisms of small intestinal obstruction following laparoscopic abdominal surgery: A retrospective multicenter study. Arch Surg 2000;135:208-212.

4. Fear RE. Laparoscopy: A valuable aid in gynecologic diagnosis. Obstet Gynecol 1968;31:297-309.

5. Helgstrand F, Rosenberg J, Bisgaard T. Trocar site hernia after laparoscopic surgery: A qualitative systematic review. Hernia 2011;15:113-121.

6. Christie MC, Manger JP, Khiyami AM, et al. Occult radiographically evident port-site hernia after robot-assisted urologic surgery: Incidence and risk factors. J Endourol 2016;30:92-96.

7. Karampinis I, Lion E, Grilli M, et al. Trocar site hernias in bariatric surgery-An underestimated issue: A qualitative systematic review and meta-analysis. Obes Surg 2019;29: 1049-1057.

8. Widmar M, Keskin M, Beltran P, et al. Incisional hernias after laparoscopic and robotic right colectomy. Hernia 2016;20:723-728.

9. Chiong E, Hegarty PK, Davis JW, et al. Port-site hernias occurring after the use of bladeless radially expanding trocars. Urology 2010;75:574-580.

10. Nezhat C, Nezhat F, Seidman DS. Incisional hernias after operative laparoscopy. J Laparoendosc Adv Surg Tech A 1997;7:111-115.

11. Susmallian S, Ezri T, Charuzi I. Laparoscopic repair of access port site hernia after lap-band system implantation. Obes Surg 2002;12:682-684.

12. Huang BS, Seow KM, Tsui KH, et al. Small trocar site hernia after laparoscopy. Gynecol Minim Invasive Ther 2013;2:79-84.

13. Owens M, Barry M, Janjua AZ, et al. A systematic review of laparoscopic port site hernias in gastrointestinal surgery. Surgeon 2011;9:218-224.

14. Swank HA, Mulder IM, La Chapelle CF, et al. Systematic review of trocar-site hernia. Br J Surg 2012;99: 315-323.

15. Fan X, Xu K, Lin T, et al. Comparison of transperitoneal and retroperitoneal laparoscopic nephrectomy for renal cell carcinoma: A systematic review and meta-analysis. BJU Int 2013;111:611-621.

16. Comajuncosas J, Vallverdú H, Orbeal R, et al. Trocar site incisional hernia in laparoscopic surgery. Cir Esp 2011;89: 72-76.

17. Huang BS, Lee FK, Wang PH. Trocar site hernia after laparoscopy, including robotic-assisted laparoscopy. J Chin Med Assoc 2014;77:59-60.

18. Payne WG, Naidu DK, Wheeler CK, et al. Wound healing in patients with cancer. Eplasty 2008;8:e9.

19. Rebibo L, Dhahri A, Chivot C, et al. Trocar site hernia after laparoscopic sleeve gastrectomy using a specific open laparoscopy technique. Surg Obes Relat Dis 2015; 11:791-796.

20. Azurin DJ, Go LS, Arroyo LR, Kirkland ML. Trocar site herniation following laparoscopic cholecystectomy and the significance of an incidental preexisting umbilical hernia. Am Surg 1995;61:718-720.

21. Mayol J, Garcia-Aguilar J, Ortiz-Oshiro ED, et al. Risks of the minimal access approach for laparoscopic surgery: Multivariate analysis of morbidity related to umbilical trocar insertion. World J Surg 1997;21: 529-533. 
22. Cybulska P, Schiavone MB, Sawyer B, et al. Trocar site hernia development in patients undergoing robotically assisted or standard laparoscopic staging surgery for endometrial cancer. Gynecol Oncol 2017;147:371-374.

23. Carlsson SV, Ehdaie B, Atoria CL, et al. Risk of incisional hernia after minimally invasive and open radical prostatectomy. J Urol 2013;190:1757-1762.

Address correspondence to:

Hooman Djaladat, MD, MS

Institute of Urology

University of Southern California

1441 Eastlake Avenue, Suite 7416

Los Angeles, CA 90089

USA

E-mail: djaladat@med.usc.edu

$\begin{aligned} & \quad \text { Abbreviations Used } \\ & \mathrm{ASA}=\text { American Society of Anesthesiologists } \\ & \mathrm{BC}=\text { bowel containing } \\ & \mathrm{BMI}=\text { body mass index } \\ & \mathrm{CCI}=\text { Charlson Comorbidity Index } \\ & \mathrm{CI}=\text { confidence interval } \\ & \mathrm{CT}=\text { computed tomography } \\ & \mathrm{F}=\text { female } \\ & \mathrm{FC}=\text { fat containing } \\ & \mathrm{HR}=\text { hazard ratio } \\ & \mathrm{IH}=\text { incisional hernia } \\ & \mathrm{L}=\text { left } \\ & \mathrm{M}=\text { male } \\ & \mathrm{PN}=\text { partial nephrectomy } \\ & \mathrm{R}=\text { right } \\ & \mathrm{RN}=\text { radical nephrectomy }\end{aligned}$

